\title{
Fixation Stability and Preferred Retinal Locus in Advanced Age-Related Macular Degeneration
}

\author{
(D) Deniz Altınbay*,**,***, (1) Şefay Aysun İdil** \\ *Özel Niv Eye Center, Adana, Turkey \\ **Ankara University Faculty of Medicine, Department of Ophthalmology, Vision Studies and Low Vision Rehabilitation Unit, Ankara, Turkey \\ ***Ankara University Graduate School of Health Sciences, Ankara, Turkey
}

\begin{abstract}
Objectives: To evaluate fixation stability and characteristics of the preferred retinal locus (PRL) in patients with advanced age-related macular degeneration (AMD).

Materials and Methods: Sixty-three eyes of 63 patients with AMD who presented to the low vision unit were included in this prospective study. Sociodemographic characteristics, eye examination findings, and reading performance results with the Minnesota Low Vision Reading test were evaluated. Microperimetry was used to evaluate fixation stability and PRL characteristics.

Results: There was unstable fixation in $68 \%$ of the eyes, relative stable fixation in $27 \%$, and stable fixation in $5 \%$. The mean PRLfoveal distance was $5.15^{\circ} \pm 3.31^{\circ}$ (range $0.75^{\circ}-14.2^{\circ}$ ). PRL-foveal distance was greater in cases with unstable fixation than cases with stable fixation ( $\mathrm{p}=0.023)$. Distance of the PRL from the lesion margin was not associated with absolute scotoma size or fixation stability $(\mathrm{p}=0.315, \mathrm{p}=0.095$, respectively). PRLs were most frequently located in the nasal quadrant $(31 \%)$, followed by the superior quadrant $(26 \%)$ of the retina. There was no significant relationship between PRL location and fixation stability $(\mathrm{p}=0.088)$. Fixation stability was significantly associated with reading speed $(\mathrm{p}=0.003)$.

Conclusion: In advanced AMD, PRL-foveal distance is an important factor in fixation stability. Knowing the factors that affect fixation stability may be important in determining low vision rehabilitation strategies for these patients because of the strong association between fixation stability and reading speed.
\end{abstract}

Keywords: Low vision rehabilitation, fixation stability, microperimetry, preferred retinal locus, age-related macular degeneration

\section{Introduction}

In age-related macular degeneration (AMD), loss of retinal sensitivity at the macula causes central scotoma, thereby reducing visual acuity and fixation stability and leading to loss of central fixation. This causes difficulty in the performance of daily activities such as reading. ${ }^{1,2}$ Oculomotor adaptation results in the formation of well-defined "preferred retinal loci" (PRLs) in the healthier regions of the retina that focus on visual targets. ${ }^{3,4}$
Microperimetry devices are currently used to evaluate the properties and stability of PRLs. ${ }^{5}$ According to the literature, $77 \%$ to $100 \%$ of patients with central scotoma develop a PRL, $1,6,7,8$ which is most commonly located in the nasal and superior retinal quadrants in $\mathrm{AMD},{ }^{7,9}$ and fixation stability was shown to be associated with PRL to fovea and lesion margin distances, lesion size, and distance visual acuity. ${ }^{1,6,9,10}$ Studies have also demonstrated a strong correlation between fixation stability and reading speed. ${ }^{11,12,13,14,15,16,17}$

Address for Correspondence: Deniz Altınbay, Özel Niv Eye Center, Adana, Turkey

E-mail: denizaltinbay01@gmail.com ORCID-ID: orcid.org/0000-0002-3976-4361

Received: 27.12.2020 Accepted: 26.03.2021

Cite this article as: Altınbay D, İdil ŞA. Fixation Stability and Preferred Retinal Locus in Advanced Age-Related Macular Degeneration. Turk J Ophthalmol 2022;52:23-29

${ }^{\circ}$ Copyright 2022 by Turkish Ophthalmological Association Turkish Journal of Ophthalmology, published by Galenos Publishing House. 
As reading speed is highly affected by fixation stability, interventions that increase fixation stability are prioritized in modern low vision rehabilitation. Microperimetric PRL training with acoustic and visual stimuli (trained retinal locus; TRL) can increase fixation stability and improve reading speed. ${ }^{18,19,20}$ Sahli et al. ${ }^{19}$ reported an increase in reading speed and quality of life with TRL training performed with microperimetric biofeedback signals in patients with central scotoma, most of whom had AMD. Therefore, evaluating fixation stability and PRL characteristics is essential in central scotoma.

This study aimed to identify factors associated with fixation stability in advanced AMD and enable our results to be applied in visual rehabilitation to increase reading speed and quality of life. There are few studies in the literature that have analyzed PRL characteristics microperimetrically in such detail, including fixation stability and reading speed, and these studies must also be conducted in languages with different reading directions. Knowing the factors affecting PRL characteristics and stability to increase fixation stability during PRL training with microperimetric acoustic and visual biofeedback signals will guide treatment planning, implementation, and follow-up.

\section{Materials and Methods}

This prospective, cross-sectional study was approved by the local clinical research ethics committee (decision no: 26.03.2018/06-363-18). All study procedures were carried out in accordance with the Declaration of Helsinki and informed consent forms were obtained from all participants.

The 63 better-seeing eyes of 63 consecutive AMD patients presenting to the vision research and low vision rehabilitation unit between August 2018 and September 2019 were included in the study. Patients who met the following criteria were included in the study: had best corrected visual acuity (BCVA) of 0.5-1.3 logMAR (Snellen 20/400-20/60) in the better-seeing eye, had atrophic AMD or stable exudative AMD not treated with intravitreal injection in the last 6 months, were over 55 years of age, were a native speaker of Turkish, and for the reading performance test, had completed at least primary school education, had the mental capacity to understand the MNREAD test rules, perform the test, and had no neurological or mental illness that would interfere with reading. Patients who declined to participate, were illiterate, had previously received low vision rehabilitation or TRL training, or were using low vision aids were excluded from the study. Patients with vision-impairing ocular pathologies other than AMD, such as diabetic retinopathy, glaucoma, optic atrophy, and hereditary retinal diseases, and those with systemic diseases that may affect vision, such as diabetes mellitus, were also excluded.

After completing the patients' sociodemographic forms, all patients underwent a detailed eye examination including BCVA assessment, anterior and posterior segment examination, low vision evaluation, MNREAD test, and contrast sensitivity (CS) test. Macular lesion size and vision-related quality of life scores were determined. The patients were asked how long they had not been able to read because of their eye problem and this time was recorded as the "reading interruption" in the data form. This information was obtained from patients and their relatives. The patients' BCVA was assessed using the Early Treatment Diabetic Retinopathy Study (ETDRS) chart as logMAR, and reading acuity was tested with MNREAD-TR and recorded in M units. CSV-1000 was used for the CS test. The classical CSV-1000 test is performed at varying spatial frequencies (3, 6, 12, and 18 cycles per degree [cpd]) at a distance of 2.5 meters. ${ }^{21}$ However, since our study group was low vision, they had difficulty at the standard test distance and the test distance and cpd values were reduced by half. The size of the macular lesion was calculated by the fundus autofluorescence Image Finder program and recorded as $\mathrm{mm}^{2}$. Visual quality of life was assessed using the NEI-VFQ25-TR, which was validated in Turkish by Toprak et al. ${ }^{22}$ The questionnaire was administered by the same technician (B.S.) and scores were calculated by the same ophthalmologist (D.A.).

Reading performance was assessed using MNREAD-TR charts, which were validated in Turkish by Idil et al..$^{23}$ The charts test near visual acuity as $\log \mathrm{MAR}$ and $\mathrm{M}(1 \mathrm{M}=0.4 \log \mathrm{MAR})$ and include 19 sentences, of which the largest is $8 \mathrm{M}(1.3 \log \mathrm{MAR})$ and the smallest is $0.12 \mathrm{M}(-0.5 \log \mathrm{MAR})$. Four parameters are evaluated: reading acuity (RA), critical print size (CPS), maximum reading speed (MRS), and the reading accessibility index (ACC). RA is the smallest print size that the person can read without significant error, MRS is the fastest reading speed when not limited by print size, and CPS is the smallest print size that can be read at this speed. Assuming the normal MRS is 200 , the average reading speed for the top 10 sentences of the MNREAD chart (the print sizes most commonly encountered in daily life) is divided by 200 to obtain ACC (normal=1.0). ${ }^{24}$

MAIA microperimetry (Centervue, Padova, Italy) was used to evaluate fixation stability and PRL characteristics. Fixation stability was determined according to Fujis clinical classification. ${ }^{25}$ This classification is based on the percentage of fixation points within a $1^{\circ}(\mathrm{P} 1)$ and $2^{\circ}(\mathrm{P} 2)$ radius of the foveal center. The presence of $75 \%$ of fixation points within the 1-degree area $(\mathrm{P} 1>75 \%)$ is regarded as stable fixation. If more than $75 \%$ of fixation points do not fall within this 1-degree area but are within the 2-degree area $(\mathrm{P} 1<75 \%$ and $\mathrm{P} 2>75 \%)$, it is called relatively stable fixation. Fixation is considered unstable when both P1 and P2 are below 75\%. Bivariate contour ellipse area is the size (in $\mathrm{mm}^{2}$ ) of the elliptical area encompassing $63 \%$ (BCEA63) and 95\% (BCEA95) of fixational eye movements. Retinal sensitivity is between 0 and 36 decibels. Macular integrity index (MII) is evaluates an individual's responses according to the age-matched mean value for the population. An MII value lower than $40 \%$ is considered normal, $40-60 \%$ is suspicious, and higher than $60 \%$ is regarded as abnormal. P1, P2, BCEA63, BCEA95, and retinal sensitivity are parameters that can be obtained directly from the microperimeter (Figure 1).

Information derived from the microperimetry test results was also used to investigate fixation characteristics. The gridshaped screen image obtained from microperimetry was printed on A4 paper and the PRL location, PRL distance from the fovea, 
PRL distance from the lesion edge, and absolute scotoma size were calculated. A ruler was used for measurements and values calculated in $\mathrm{mm}$ were converted to degrees and recorded (1 square in the grid of the microperimeter screen corresponds to 1 degree). If the location of the fovea could not be determined because of advanced AMD, an estimated location of the fovea was marked at $15.5^{\circ}$ temporal and $1.3^{\circ}$ inferior to the optic disc center. ${ }^{26}$ To describe PRL location, the retina was divided into 4 equal quadrants centered on the fovea and PRL location was classified as superior, inferior, temporal, nasal, or central (within $4^{\circ}$ of the foveal center) (Figure 2). ${ }^{9}$ All measurements were performed by a single ophthalmologist (D.A.) to avoid interobserver variability.

\section{Statistic Analysis}

The IBM SPSS Statistics version 20.0 package (IBM Corp, Armonk, NY) was used for statistical analyses. For numerical measurements, the assumption of normal distribution was tested using the Shapiro-Wilk test and comparisons of means between two groups were performed using t-test or Mann-Whitney U test as necessary. Comparisons between multiple groups were performed using one-way analysis of variance or the KruskalWallis test. Bonferroni, Scheffe, and Tamhane tests were used as appropriate for pairwise comparisons between groups. In all tests, $\mathrm{p}<0.05$ was accepted as significant.

\section{Results}

The study included 41 men and 22 women with a mean age of $77.49 \pm 8.56(58-93)$ years. The left eyes of 36 patients $(57 \%)$ and the right eyes of 27 patients (43\%) were included. The mean symptom duration was $4.73 \pm 4.09$ years, daily reading habit was $2.1 \pm 2.23$ hours, reading interruption was $2.58 \pm 3.08$ years, vision-related quality of life score was $47.5 \pm 11.4$, and the near activities subscale score was $29.0 \pm 12.4$.

The patients' mean distance and near visual acuities were $0.66 \pm 0.2 \log \mathrm{MAR}$ and $2.63 \pm 2.46 \mathrm{M}$, respectively. AMD was atrophic in $48 \%$ of the patients and exudative in $52 \%$; lesion size ranged from 1.110 to $24.568 \mathrm{~mm}^{2}$ (mean $7.162 \pm 4.671$ $\mathrm{mm}^{2}$ ). CS test results were $10.62 \pm 9.49 \mathrm{~dB}$ and $4.46 \pm 3.93 \mathrm{~dB}$ for $1.5 \mathrm{cpd}$ and $3 \mathrm{cpd}$ (low spatial frequencies) and $12.3 \pm 11.2$ $\mathrm{dB}$ and $21.0 \pm 15.1 \mathrm{~dB}$ for $6 \mathrm{cpd}$ and $9 \mathrm{cpd}$ (medium spatial frequencies), respectively. According to the MNREAD chart, mean RA was $0.86 \pm 0.34 \log \mathrm{MAR}$ (range, 0.12-1.80 $\log \mathrm{MAR}$ ), CPS was $1 \pm 0.35 \operatorname{logMAR}$ (range, 0.32-1.90 logMAR), MRS was 70.2 \pm 37.23 words/min (wpm) (range, 19-160 wpm), and ACC was $0.27 \pm 0.21$ (range, 0-0.69).

Retinal sensitivity, P1, P2, BCEA63, and BCEA95 values were obtained directly from microperimetry. Fixation stability was unstable in 43 eyes (68\%), relatively stable in 17 eyes $(27 \%)$, and stable in 3 eyes $(5 \%)$ (Table 1 ). Retinal location of the PRL was nasal in $31 \%$, superior in $19 \%$, inferior in $16 \%$, central in $16 \%$, and temporal in $11 \%$ of eyes. In left eyes, the most common location was the nasal quadrant (36\%), while in right eyes, the most common location was the superior quadrant $\left(31 \%\right.$ ). The mean PRL-fovea distance was $5.15^{\circ} \pm 3.31^{\circ}$ (range,

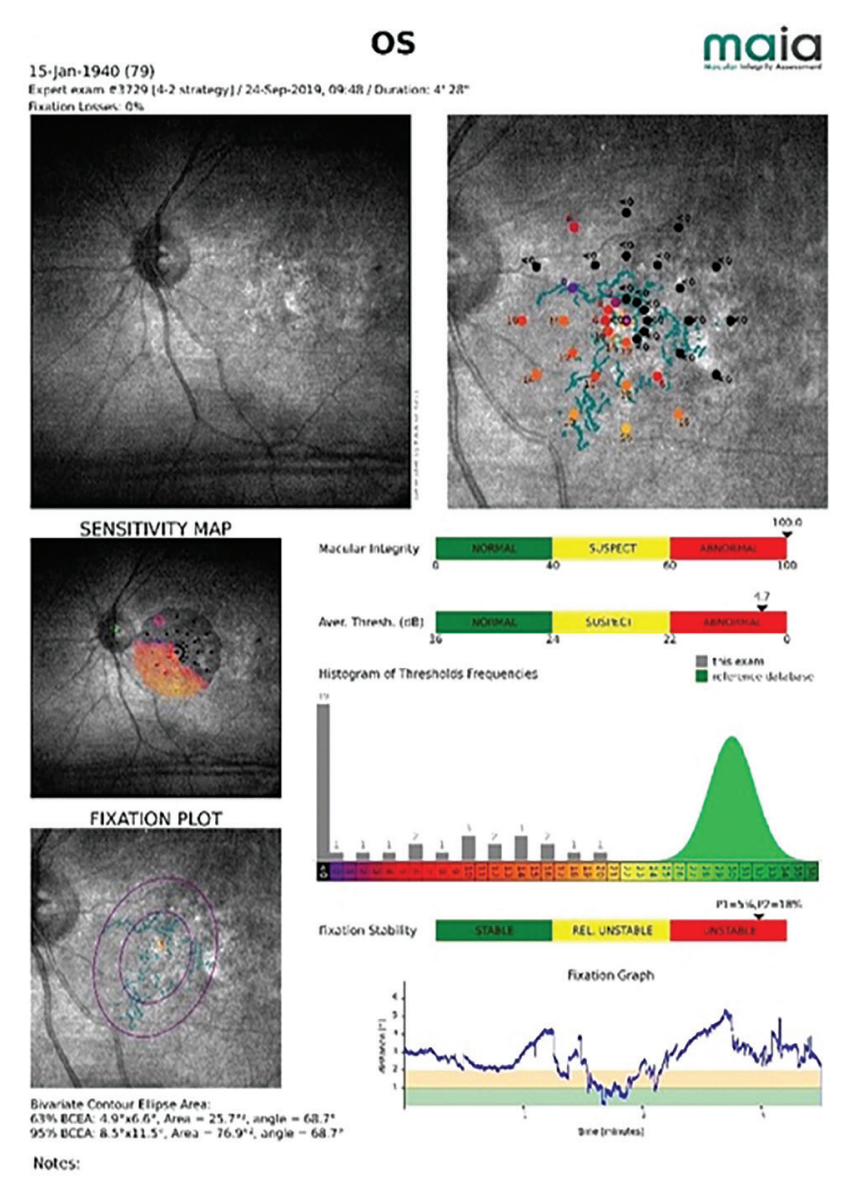

Figure 1. Example of microperimetry output for an eye with AMD AMD: Age-related macular degeneration

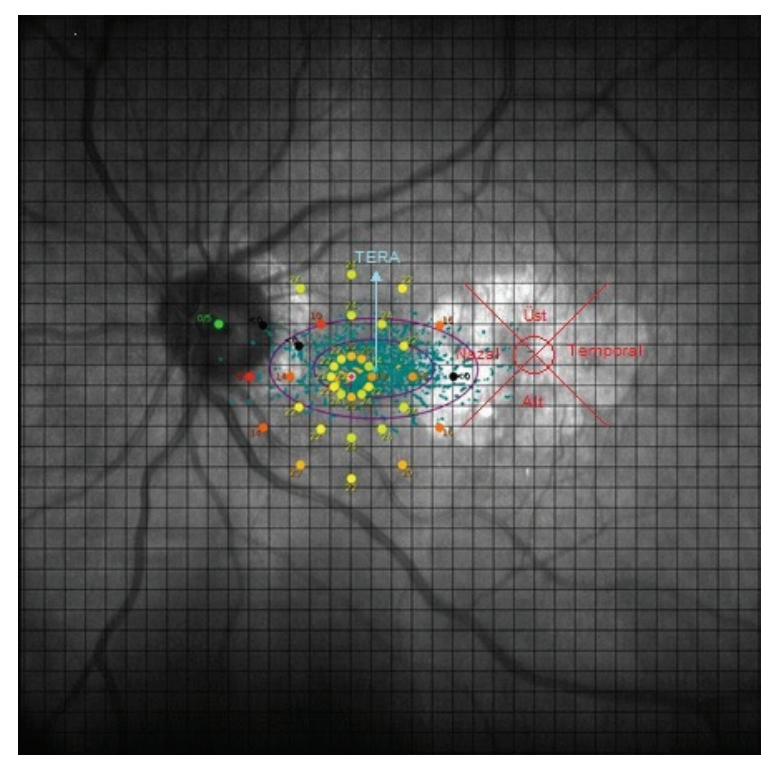

Figure 2. Division of the retina into quadrants centered on the fovea 
$0.75^{\circ}-14.2^{\circ}$ ). The PRL was to the left of the absolute scotoma in $29 \%$ of eyes and to the right in $22 \%$ of eyes. The mean absolute scotoma size was $16^{\circ} \pm 15^{\circ}$ (range, $0^{\circ}-62^{\circ}$ ). Forty-two eyes $(67 \%$ ) had absolute scotoma at the fovea. The results obtained from microperimetry indirectly using special measurements are shown in Table 2.

There was no statistically significant relationship between fixation stability and distance or near visual acuity $(\mathrm{p}=0.072$ and $\mathrm{p}=0.312$, respectively). When the stable and relatively stable fixation groups were combined, distance visual acuity was significantly lower in eyes with unstable fixation compared to those with stable or relatively stable fixation ( $\mathrm{p}=0.041)$. Reading

\begin{tabular}{|c|c|c|}
\hline & & Mean \pm SD \\
\hline \multicolumn{2}{|l|}{ MII } & $99.8 \pm 1.6$ \\
\hline \multicolumn{2}{|c|}{ Mean retinal sensitivity (dB) } & $10.8 \pm 6.5$ \\
\hline \multicolumn{2}{|l|}{$\mathrm{P} 1$} & $25.5 \pm 20.4$ \\
\hline \multicolumn{2}{|l|}{$\mathrm{P} 2$} & $56.2 \pm 23.4$ \\
\hline \multicolumn{2}{|l|}{ BCEA 63} & $17.3 \pm 10.8$ \\
\hline \multirow{2}{*}{\multicolumn{2}{|c|}{ BCEA 95}} & $51.6 \pm 32.4$ \\
\hline & & n $(\%)$ \\
\hline \multirow{3}{*}{ Fixation stability } & Stable & $3(5)$ \\
\hline & Relatively stable & $17(27)$ \\
\hline & Unstable & $43(68)$ \\
\hline \multicolumn{3}{|c|}{$\begin{array}{l}\text { MII: Macular Integrity Index, P1: Percentage of fixation points in a } 1^{\circ} \text { radius circle, P2: } \\
\text { Percentage of fixation points in a } 2^{\circ} \text { radius circle, BCEA: Bivariate contour ellipse area, SD: } \\
\text { Standard deviation }\end{array}$} \\
\hline
\end{tabular}

\section{Table 2. Results derived from microperimetry}

\begin{tabular}{|c|c|c|}
\hline & Mean \pm SD \\
\hline \multicolumn{2}{|l|}{ PRL-fovea distance $\left(^{\circ}\right)$} & $5.15 \pm 3.31$ \\
\hline \multicolumn{2}{|c|}{ PRL-lesion margin distance $\left(^{\circ}\right)$} & $1.84 \pm 2.66$ \\
\hline \multicolumn{2}{|l|}{ Absolute scotoma size $\left(^{\circ}\right)$} & $16.0 \pm 15.0$ \\
\hline & & $\mathrm{n}(\%)$ \\
\hline \multirow{5}{*}{ PRL location } & Nasal quadrant & $19(31)$ \\
\hline & Superior quadrant & $16(26)$ \\
\hline & Inferior quadrant & $10(16)$ \\
\hline & Central & $10(16)$ \\
\hline & Temporal quadrant & $7(11)$ \\
\hline \multirow{6}{*}{$\begin{array}{l}\text { PRL location relative to } \\
\text { absolute scotoma }\end{array}$} & Left of the scotoma & $18(29)$ \\
\hline & In the scotoma & $14(22)$ \\
\hline & No absolute scotoma & $11(17)$ \\
\hline & Below the scotoma & $9(14)$ \\
\hline & Right of the scotoma & $7(11)$ \\
\hline & Above the scotoma & $4(6)$ \\
\hline \multirow{2}{*}{ Foveal absolute scotoma } & Yes & $42(67)$ \\
\hline & No & $21(33)$ \\
\hline
\end{tabular}

speed was $148.7 \pm 12.7 \mathrm{wpm}$ in the stable fixation group, $80.9 \pm 41.1 \mathrm{wpm}$ in the relatively stable group, and $60.5 \pm 28.5$ wpm in the unstable fixation group. There was a statistically significant relationship between reading speed and fixation stability $(\mathrm{p}=0.003)$. In the unstable fixation group, CS values at low (3 cpd) and medium (6 cpd and 9 cpd) spatial frequencies were lower compared to the relatively stable fixation group ( $\mathrm{p}=0.019, \mathrm{p}=0.038$, and $\mathrm{p}=0.011$, respectively).

There was no significant relationship between fixation stability and the retinal location of the PRL and whether this location was in the right or left eye $(\mathrm{p}=0.088$ and $\mathrm{p}=0.199$, respectively). Fixation stability also showed no statistical association with absolute scotoma size $(\mathrm{p}=0.095)$, PRL location relative to the absolute scotoma $(\mathrm{p}=0.05)$, or distance of the PRL to the lesion margin $(\mathrm{p}=0.315)$. However, distance of the PRL to the fovea was significantly associated with fixation stability $(\mathrm{p}=0.023)$ (Table 3).

The PRL was significantly farther from the fovea in eyes with unstable fixation than in eyes with stable fixation ( $p=0.023)$. The relationship between PRL-fovea distance and fixation stability is shown in Figure 3.

\section{Discussion}

PRLs that develop through adaptive mechanisms for fixation in advanced AMD are generally extrafoveal and unstable, which are critical factors in reducing reading ability. It has been reported that fixation stability is strongly associated with reading speed, ${ }^{11-17}$ and is affected by distance visual acuity, lesion size, and PRL distance to the fovea and lesion margin. ${ }^{1,6,9,10}$ In our study, we observed that PRLs were extrafoveal in $85 \%$ and unstable in $68 \%$ of eyes with advanced AMD, fixation stability was affected by PRL-fovea distance, and there was a strong association between fixation stability and reading speed.

Studies have shown that the PRL, which replaces the nonfunctioning fovea in eyes with central scotoma, is less stable as its distance from the fovea increases. ${ }^{6,9,10,27}$ The mean PRLfovea distance in AMD was reported to be $6.69^{\circ} \pm 7.4^{\circ}$ by Erbezci and Oztürk ${ }^{9}$ and $6.25^{\circ} \pm 2.38^{\circ}$ by Sahli et al., ${ }^{19}$ while Fujita et al..$^{28}$ reported distances between $5^{\circ}$ and $11^{\circ}$. In our study, the mean PRL-fovea distance was $5.15^{\circ} \pm 3.31^{\circ}$ (range, $0.75^{\circ}-14.2^{\circ}$ ). This value was determined to be $5.64^{\circ} \pm 3.41^{\circ}$ in the unstable fixation group and $2.04^{\circ} \pm 0.56^{\circ}$ in the stable fixation group, showing that the PRL-fovea distance was greater in eyes with unstable fixation compared to those with stable fixation. We attribute the effect of PRL-fovea distance on fixation stability to the fact that retinal resolution and sensitivity are highest at the fovea. Chung et al. ${ }^{29}$ reported that retinal resolution decreased further from the fovea.

Various studies have demonstrated that reading speed decreases with poorer fixation stability. ${ }^{11-17}$ In our study, reading speed was $148.7 \pm 12.7 \mathrm{wpm}$ in the stable fixation group, $80.9 \pm 41.1 \mathrm{wpm}$ in the relatively stable group, and $60.5 \pm 28.5$ wpm in the unstable group. There was a strong statistical association between reading speed and fixation stability 


\begin{tabular}{|c|c|c|c|c|}
\hline \multirow{3}{*}{ Characteristic } & \multicolumn{3}{|c|}{ Fixation Stability } & \multirow{3}{*}{$\mathbf{p}$} \\
\hline & Stable & Relatively stable & Unstable & \\
\hline & Mean \pm SD & Mean \pm SD & Mean \pm SD & \\
\hline Distance visual acuity (logMAR) & $0.50 \pm 0.0$ & $0.62 \pm 0.23$ & $0.68 \pm 0.20$ & 0.072 \\
\hline Near visual acuity $(\mathrm{M})$ & $1.2 \pm 0.35$ & $3.04 \pm 2.98$ & $2.57 \pm 2.3$ & 0.312 \\
\hline Lesion size $\left(\mathrm{mm}^{2}\right)$ & $4963.0 \pm 6268.9$ & $6764.9 \pm 6518.4$ & $7472.4 \pm 3694.4$ & 0.131 \\
\hline Maximum reading speed (wpm) & $148.7 \pm 12.7$ & $80.9 \pm 41.1$ & $60.5 \pm 28.5$ & 0.003 \\
\hline Low-frequency CS (1.5 cpd) (dB) & $10.0 \pm 5.0$ & $15.35 \pm 13.73$ & $11.26 \pm 10.26$ & 0.264 \\
\hline Low-frequency CS (3 cpd) (dB) & $10.67 \pm 4.62$ & $30.47 \pm 19.7$ & $17.91 \pm 11.57$ & 0.019 \\
\hline Mid-frequency CS (6 cpd) (dB) & $5.33 \pm 2.31$ & $16.71 \pm 13.34$ & $8.58 \pm 6.6$ & 0.038 \\
\hline Mid-frequency CS (9 cpd) (dB) & $3.33 \pm 3.18$ & $7.06 \pm 5.8$ & $3.51 \pm 2.39$ & 0.011 \\
\hline Absolute scotoma size $\left(^{\circ}\right)$ & $6.33 \pm 10.97$ & $11.35 \pm 11.45$ & $18.53 \pm 15.89$ & 0.095 \\
\hline PRL-lesion margin distance $\left(^{\circ}\right)$ & $0 \pm 0$ & $1.52 \pm 1.24$ & $2.08 \pm 3.03$ & 0.315 \\
\hline \multirow[t]{2}{*}{ PRL-fovea distance $\left(^{\circ}\right)$} & $2.04 \pm 0.56$ & $4.49 \pm 3.00$ & $5.64 \pm 3.41$ & 0.023 \\
\hline & n (\%) & n (\%) & n (\%) & \\
\hline \multicolumn{4}{|l|}{ Retinal location of PRL } & \multirow{6}{*}{0.088} \\
\hline Inferior quadrant & $1(33)$ & $2(12)$ & $7(17)$ & \\
\hline Nasal quadrant & $0(0)$ & $6(35)$ & $13(31)$ & \\
\hline Central & $2(67)$ & $3(18)$ & $5(12)$ & \\
\hline Superior quadrant & $0(0)$ & $2(12)$ & $14(33)$ & \\
\hline Temporal quadrant & $0(0)$ & $4(24)$ & $3(7)$ & \\
\hline \multicolumn{4}{|c|}{ PRL location relative to absolute scotoma } & \multirow{7}{*}{0.050} \\
\hline Right & $0(0)$ & $3(18)$ & $4(9)$ & \\
\hline Left & $0(0)$ & $7(41)$ & $11(\% 26)$ & \\
\hline Inside & $0(0)$ & $0(0)$ & $14(33)$ & \\
\hline Below & $1(33)$ & $1(6)$ & $7(16)$ & \\
\hline Above & $0(0)$ & $2(12)$ & $2(5)$ & \\
\hline No absolute scotoma & $2(67)$ & $4(24)$ & $5(12)$ & \\
\hline
\end{tabular}

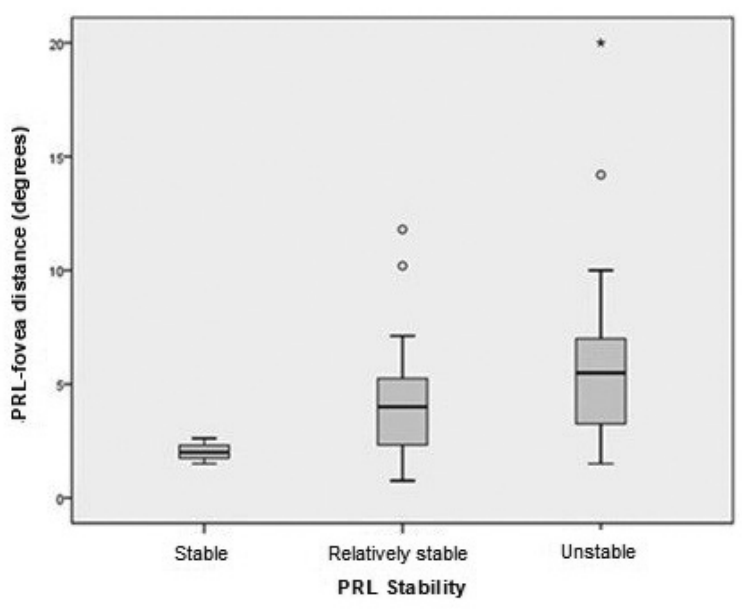

Figure 3. Relationship between fixation stability and PRL-fovea distance ( ${ }^{\circ}$ outlier, *extreme outlier)

PRL: Preferred retinal loci
( $\mathrm{p}=0.003)$. Reading function requires good detail detection, which itself requires foveal and stable fixation. Giacomelli et al. ${ }^{17}$ stated that improved fixation translated to improved visual capacity. We believe that the decrease in reading speed associated with poorer fixation stability is related to this.

In the literature, single/multiple PRL development in AMD has been reported at different rates $(77 \%-100 \%),{ }^{1,6,7,8}$ and most are located extrafoveally. Greenstein et al. ${ }^{6}$ reported that all patients in their study developed a PRL, of which $73.3 \%$ were extrafoveal and $26.6 \%$ were foveal in location. In our study, we observed that $98.4 \%$ of patients developed a single PRL that was extrafoveal in $84 \%$ and foveal in $16 \%$ of the eyes. Fixation was unstable in $68 \%$, relatively stable in $27 \%$, and stable in $5 \%$ of the cases. We attribute the low fixation stability in our study to the patients having low vision, advanced AMD, symptom duration longer than 6 months, and mostly extrafoveal PRLs. Karaçorlu et al. ${ }^{30}$ also observed no stable and central fixation in patients with symptom duration longer than 6 months. 
Retinal localization of PRLs is still not fully understood, and in $25 \%$ of cases the PRL is not in a favorable location. ${ }^{31}$ While there are some studies suggesting that location may be relevant in terms of reading, ${ }^{7,32}$ others showed no relationship between PRL location and reading speed. ${ }^{2,33,34}$ Evidence indicates that PRLs are usually located to the left of the scotoma. ${ }^{1,2,7,9,35}$ However, PRLs can develop in any retinal quadrant., ${ }^{9,34,35}$ In AMD, the most common PRL location is the nasal quadrant, followed by the superior quadrant. ${ }^{7,9,19}$ Similarly, in our study, we determined that the PRL was located in the nasal retinal quadrant in $31 \%$, superior quadrant in $26 \%$, inferior quadrant in $16 \%$, and temporal quadrant in $11 \%$ of eyes, while $16 \%$ of PRLs were located centrally. We detected no statistically significant relationship between PRL location and fixation stability. Similarly, Farzaneh et al. ${ }^{27}$ found no significant relationship between PRL location on the retina and fixation stability in native Persian-speaking AMD patients.

Erbezci and Oztürk ${ }^{9}$ reported that fixation stability was associated with distance BCVA and that fixation in the affected eye became unstable with greater PRL-fovea distance, PRL to lesion margin distance, and lesion size. When we grouped the eyes in our study as stable, relatively stable, and unstable, distance BCVA was not associated with fixation stability. However, when we combined the stable and relatively stable group, a statistically significant relationship emerged. The absence of a statistical relationship initially is likely due to the small number of eyes in the stable fixation group. Similarly, in our study there was no statistically significant relationship between fixation stability and scotoma size or PRL-lesion margin distance, but we observed that scotomas were larger and PRLs further from the lesion margin in eyes with unstable fixation.

Spatial and temporal CS tests in patients with maculopathy have demonstrated moderate to strong correlation between reading speed and CS. ${ }^{36}$ In our study, eyes with unstable fixation showed lower CS at low and medium spatial frequencies compared to eyes with relatively stable fixation. This may be related to the higher PRL-fovea distance in this group and the lower retinal sensitivity and resolution in this area of the retina.

\section{Study Limitations}

CS tests modified for people with low vision could not be used for our patients because they were not available in our clinic. In addition, as all participants were Turkish-speakers, studies with broader participation in different languages are needed to investigate the effect of PRL location on the retina on fixation stability.

\section{Conclusion}

In this study, we observed that fixation stability was affected by PRL distance from the fovea and was strongly associated with reading speed. Given the close relationship between fixation stability and reading speed, awareness of the factors affecting fixation stability in advanced AMD is crucial to restore reading ability in low vision rehabilitation. The results of this study may be both strategically and prognostically useful in the planning and implementation of microperimetric treatment (TRL) to improve fixation stability in low vision rehabilitation centers.

Acknowledgements: This article was created from the master's thesis titled "The Effect of Microperimetric Characteristics on Reading Performance in Low Vision Patients with Age-Related Macular Degeneration" completed by the first author (D.A.) for the Graduate Degree in Vision, Artificial Vision, and Low Vision Rehabilitation program of Ankara University Graduate School of Health Sciences, with funding from the Ankara University Scientific Research Projects Directorate (project number 18L0230015).

Ethics

Ethics Committee Approval: This prospective, crosssectional study was approved by the local clinical research ethics committee (decision no: 26.03.2018/06-363-18).

Informed Consent: Obtained.

Peer-review: Externally peer reviewed.

Authorship Contributions

Surgical and Medical Practices: D.A., S.A.I., Concept: D.A., S.A.İ., Design: D.A., S.A.İ., Data Collection or Processing: D.A., Analysis or Interpretation: D.A., S.A.İ, Literature Search: D.A., Writing: D.A.

Conflict of Interest: No conflict of interest was declared by the authors.

Financial Disclosure: The authors declared that this study received no financial support.

\section{References}

1. Fletcher DC, Schuchard RA. Preferred Retinal Loci Relationship to macular Scotomas in a Low Vision Population. Ophthalmology. 1997;104:632-638.

2. Fletcher DC, Schuchard RA, Watson G. Relative Location of Macular Scotomas Near the PRL: Effect on Low Vision Reading. J Rehabil Res Dev. 1999;36:356-364.

3. Crossland MD, Engel SA, Legge GE. The Preferred Retinal Locus in Macular Disease. Toward a Consensus Definition. Retina. 2011;31:2109-2114.

4. Ceyhan D. Maküla hastalıklarında görme rehabilitasyonu. Ret-Vit. 2010;18:Özel Say1:151-157.

5. Fuji GY, De Juan E JR, Humayun MS, Sunness JS, Chang TS, Rossi JV. Characteristics of visual loss by scanning laser ophthalmoscope microperimetry in eyes with subfoveal choroidal neovascularization secondary to age-related macular degeneration. Am J Ophthalmol. 2003;136:1067-1078.

6. Greenstein VC, Santos RA, Tsang SH, Smith RT, Barile GR, Seiple W. Preferred Retinal Locus İn Macular Disease: Characteristics And Clinical İmplications. Retina. 2008;28:1234-1240.

7. Sunness JS, Applegate Ca. Long-Term Follow-Up Of Fixation Patterns in Eyes With Central Scotomas From Geographic Atrophy That is Associated With Age-Related Macular Degeneration. Am J Ophthalmol. 2005;140:10851093.

8. Antunes-Foschini RMS, Ho W, Messias A. Eccentric fixation patterns, clinical findings, and reading speed in patients with bilateral toxoplasmic macular retinochoroiditis. Arq Bras Oftalmol. 2018;81:401-407.

9. Erbezci M, Ozturk. Preferred Retinal Locus Locations in Age-Related Macular Degeneration. Retina. 2018;38:2372-2378.

10. Mori F, Ishiko S, Kitaya N, Takamiya A, Sato E, Hikichi T, Yoshida A. Scotoma and fixation patterns using scanning laser ophthalmoscope microperimetry in patients with macular dystrophy. Am J Ophthalmol. 2001;132:897-902. 
11. Calabrese A, Bernard B, Faure G, Hoffart L, Castet E. Clustering Of Eye Fixations: A New Oculomotor Determinant of Reading Speed in Maculopathy. Invest Ophthalmol Vis Sci. 2016;57:3192-3202.

12. Deruaz A, Matter M, Whatham AR, Goldschmidt M, Duret F, Issenhuth M, Safran AB. Can fixation instability improve text perception during eccentric fixation in patients with central scotomas. Br J Ophthalmol. 2004;88:461463.

13. Şentürk F, Karaçorlu Arf S, Özdemir H, Karaçorlu M. Cografik atrofili gözlerdeki fiksasyon özelliklerinin MP-1 mikroperimetri ile degerlendirilmesi. Retina-Vitreus. 2006;14:41-44.

14. Crossland MD, Culham LE, Rubin GS. Fixation Stability And Reading Speed İn Patients With Newly Developed Macular Disease. Ophthalmic Physiol Opt. 2004;24:327-333.

15. Whittaker SG, Cummings RW, Swieson L. Saccade control without a fovea. Vision Res. 1991;31:2209-2218.

16. Fujita K, Naruse M, Oda K, Yuzawa M. Reading Performance in The Scar Stage Of Age-Related Macular Degeneration. Nippon Ganka Gakkai Zasshi. 2005;109:83-87.

17. Giacomelli G, Virgili G, Giansanti F, Sato G, Cappello E, Cruciani F, Varano M, Menchini U. Clinical And Microperimetric Predictors Of Reading Speed in Low Vision Patients: A Structural Equation Modeling Approach. Invest Ophthalmol Vis Sci. 2013;54:4403-4408.

18. Tarita-Nistor L, Gonzalez EG, Markowitz SN, Steinbach MJ . Plasticity of Fixation İn Patients With Central Vision Loss. Vis Neurosci. 2009;26:487494.

19. Sahli E, Altinbay D, Bingol Kiziltunc P, Idil A. Effectiveness of Low Vision Rehabilitation Using Microperimetric Acoustic Biofeedback Training in Patients with Central Scotoma. Curr Eye Res. 2020;18:731-738.

20. Molina-Martín A, Pérez-Cambrodí RJ, Piñero DP. Current Clinical Application of Microperimetry: A Review. Semin Ophthalmol. 2018;33:620-628.

21. Rodriguez -Galietero A M-Mr, Munoz G, Alberran -Diego C. Comparison Of Contrast Sensitivity And Color Discrimination After Clear And Yellow İntraocular Lens İmplantation. J Catarct Refract Surg. 2005;31:1736-1740.

22. Toprak AB, Eser E, Guler C, Baser FE, Mayalı H. Cross Validation Of Turkish Version 25 İtem National Eye İnstitute Visual Functioning Questionnarie (NEIVFQ- 25). Ophthalmic Epidemiol. 2005;12:259-269.

23. İdil AŞ, Çalışkan D, İdil BN. The development and validation of MNREAD acuity charts in Turkish. Turk J Ophthalmol. 2009;39:84-90.

24. Calabrèse A, Owsley C, McGwin G, Legge GE. Development of a Reading Accessibility Index Using the MNREAD Acuity Chart. JAMA Ophthalmol. 2016;134:398-405.
25. Fuji GY, De Juan E, Jr, Sunnes J, Humayun Ms, Pieramici DJ, Chang TS Patient Selection For Macular Translocation Surgery Using The Scanning Laser Ophthalmoscope. Ophthalmology. 2002;109:1737-1744.

26. Tarita-Nistor L, Gonzalez EG, Markowitz SN, Steinbach MJ. Fixation Characteristics of Patients With Macular Degeneration Recorded With The Mp-1 Microperimeter. Retina. 2008;28:125-133.

27. Farzaneh A, Riazi A, Khabazkhoob M, Doostdar A, Farzaneh M, Falavarjani KG. Location and stability of the preferred retinal locus in native Persianspeaking patients with age-related macular degeneration. Clin Exp Optom. 2021;104:194-200.

28. Fujita K, Yuzawa M. [Preferred retinal locus in patients with age-related macular degeneration]. Nippon Ganka Gakkai Zasshi. 2003;107:602-606.

29. Chung ST, Mansfield JS, Legge GE. Psychophysics Of Reading. XVIII. The Effect Of Print Size On Reading Speed İn Normal Peripheral Vision. Vision Res. 1998;38:2949-2962.

30. Karaçorlu M, Sentürk F, Özdemir H, Karaçorlu SA, Uysal Ö. Yaşa bağlı maküla dejenerasyonuna sekonder klasik subfoveal koroid neovaskülarizasyonunda semptom süresi ile mikroperimetrik değişiklikler arasındaki ilişki. Türk Oftalmoloji Gazetesi. 2008;38:330-335.

31. Midena E, Pilotto E. Microperimetry İn Age-Related Macular Degeneration. Eye (Lond). 2017;31:985-994.

32. Nilsson UL, Frennesson C, Nilsson SE. Patients with AMD and a large absolute central scotoma can be trained successfully to use eccentric viewing, as demonstrated in a scanning laser ophthalmoscope. Vision Res. 2003;43:17771787.

33. Antunes-Foschini RMS, Ho W, Messias A. Eccentric fixation patterns, clinical findings, and reading speed in patients with bilateral toxoplasmic macular retinochoroiditis. Arq Bras Oftalmol. 2018;81:401-407.

34. Crossland MD, Culham LE, Kabanarou SA, Rubin GS. Preferred Retinal Locus Development in Patients With Macular Disease. Ophthalmology. 2005;112:1579-1585.

35. Sunness JS, Applegate CA, Haselwood D, Rubin GS. Fixation patterns and reading rates in eyes with central scotomas from advanced atrophic age-related macular degeneration and Stargardt disease. Ophthalmology. 1996;103:14581466.

36. Brussee T, Van Den Berg Tjtp, Van Nispen Rma, De Boer I, Van Rens Ghmb. Association Between Contrast Sensitivity And Reading With Macular Pathology. Optom Vis Sci. 2018;95:183-192. 